\title{
УПРАВЛЕНИЕ МОДЕРНИЗАШИЕЙ
}

М. А. Оруджева

\section{МЕТОДЫ УПРАВЛЕНИЯ И КОНТРОЛЯ РЕСУРСАМИ ЖИЛИЩНО-КОММУНАЛЬНОГО КОМПЛЕКСА НА ОСНОВЕ СРАВНИТЕЛЬНОГО АНАЛИЗА ЗАРУБЕЖНОГО И ОТЕЧЕСТВЕННОГО ОПЫТОВ}

Аннотация. Предметом исследования является изменение жилищной политики. ЖКХ, как один из социальных стратегически значимых объектов общества, претерпевает во всем мире существенные изменения. Единого сценария не существует, но отдельные, наиболееуспешные примеры использованы в качествемоделей, которые адаптируются кпотребностям российского жилищно-коммунального хозяйства. Рассмотрен зарубежный опыт по повышению качества трудовых ресурсов и ресурсосбережению путем введения инновационных методик. В качестве объекта исследования взяты предприятия ЖКХпо водоснабжениюи водоотведению: Акционерное Общество «Азерсу» (Азербайджан) и МУП «ЖКХ «Холмские» (Россия, Краснодарский край). Методом исследования послужил сравнительный анализ различий между моделями управления зарубежным и отечественным ЖКХсточки зрения особенностей национальной политики и экономического развития. Научная новизна состоит в изучении передового зарубежного опыта с выявлением основных направлений его применения в российских условиях: внедрения новых технологий, повышения качества услуг, мотивации труда, ресурсосбережения и др. Даны рекомендации по их внедрению в российский опыт. Применительно исследуемого предприятия была проведена программа по повышению качества и мотивации труда.

Ключевые слова: ресурсосбережение, трудовые ресурсы, инновачионная модернизация, зарубежный опыт, денежные ресурсы, задолженность населения, основные фонды, изношенность, водные ресурсы, мониторинг.

Review. The subject of this research is the change in housing policies. Housing and utilities, as one of the strategically-important institutes of society, is undergoing a series of significant changes all around the globe. There is no singular, universal scenario, but the most successful examples are used as models that are being adapted to the demands and realities of Russian housing and communal services. The author examines foreign experience of enhancing the quality of labour and supplying resources by implementing innovative methods. As the object of research, the author chose housing and communal water supply and drain enterprises: The Joint stock company "Azersu" (Azerbaijan) and the Municipal Unitary Enterprise "Housing and Utilities "Kholmskiye" (Russia, Krasnodar Region). The method of this research is the comparative analysis of the differences between the models of administration between foreign and Russian Housing and utilities from the standpoint of domestic policies and economy development. The scientific novelty of this work is based on studying the cutting-edge foreign experience that permits to discover the main directions of its application in Russia conditions in light of implementing new technologies, enhancing the quality of service, motivation of labour, supplying resources, etc. The author gives recommendations on implementing such novelties into Russian practices. As applied to the enterprises being examined, a program for enhancing the quality and motivation of labour has been introduced.

Keywords: depreciation, fixed assets, debt population, financial resources, foreign experience, innovative modernization, human resources, resource conservation, water resources, monitoring.

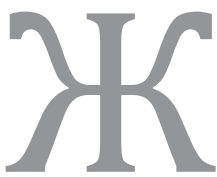
илищная политика претерпевает во всем мире существенные изменения. В последние два десятилетия реструктуризацию отрасли ЖКХ проводят более 100 стран мира [1]. Единого сценария не существует, но отдельные, наиболее успешные примеры используются в качестве моделей, которые адаптируются к потребностям определенного государства. Для осознания процессов, происходящих в настоящее время в России и выбора оптимальной модели управления собственностью жилищного сектора необходимо проанализировать достоинства и недостатки существующих моделей управления в ряде европейских стран. Основные различия заключаются в методах управления сферой ЖКХ, выбор которых продиктован культурой управления в стране и экономическими особенностями последней.

Проблемы жилищно-коммунального хозяйства зарубежных стран предопределили единство целей радикального преобразования этой сферы и общих направлений совершенствования всей совокупности отношений, возника- 
ющих в процессе производства и потребления жилищно-коммунальныхуслуг [2]. Поэтому цель данной статьи заключается в анализе различий между моделями управления зарубежными и отечественными ЖКХ с точки зрения особенностей национальной политики и экономического развития и выборе приемлемой модели для российских ЖКХ.

Надо отметить, что реформирование отраслей городского хозяйства, в которых существуют коммунальные предприятия, в зарубежных странах проходило в рамках общих программ приватизации публичной собственности. Для сравнительного анализа деятельности с целью выведения наилучшего зарубежного опыта мы выбрали Азербайджанскую АР, республику, входящую в состав бывшего СССР. Выбор обусловлен тем, что в период существования СССР все страны содружества имели центральное финансирование и одинаковые возможности для деятельности развития, а в 90-е годы все страны бывшего СССР имели схожую базу коммунально-жилищного фонда. Поэтому для сравнительного анализа целесообразно было взять объект, имеющий те же возможности и уровень основных средств, что в российском предприятии ЖКХ. После распада СССР, жилищно-коммунальная сфера всех стран содружества имела примерно одинаковый уровень развития и состояние фондов.

В качестве объекта исследования взяты предприятия ЖКХ по водоснабжению и водоотведению: Акционерное Общество «Азерсу» (Азербайджан) и МУП «ЖКХ «Холмские» (Россия, Краснодарский край). Рассмотрим основные сходства и различия «Азерсу»и МУП «ЖКХ «Холмские».

Таблица 1

Сравнительная характеристика «Азерсу» и МУП «ЖКХ «Холмские» как объектов исследования

\begin{tabular}{|l|l|l|}
\hline \multicolumn{1}{|c|}{ Основные черты } & \multicolumn{1}{|c|}{ «Азерсу» } & МУЖКХ «Холмские» \\
\hline Форма собственности & акционерное общество & муниципальное унитарное предприятие \\
\hline Направленность & социальная & социальная \\
\hline Ориентация на прибыль & коммерческое & водоснабжение, водоотведение \\
\hline Вид деятельности & водоснабжение, водоотведение & административное управление \\
\hline Принципы функционирования & рыночные & государство \\
\hline Собственник & государство & монополия \\
\hline Форма конкуренции & монополия & гранды \\
\hline Финансирование & дотации & с ограничителем \\
\hline Тарифное регулирование & с ограничителем & после оказываемых услуг \\
\hline Система оплаты за жку & до оказываемых услуг & нет \\
\hline Программы по мотивации труда & есть & $\begin{array}{l}\text { Распределение в процентном } \\
\text { соотношении среди всего персонала }\end{array}$ \\
\hline Премирование работников & $\begin{array}{l}\text { По собесесуовованию и предъявлению } \\
\text { свидетельства о проф.образовании } \\
\text { занятиями }\end{array}$ \\
\hline Принятие на работу соискателя экаменации на \\
\hline
\end{tabular}




\section{Тренды и управление 3(11) • 2015}

Оба предприятия являются коммерческими и имеют одинаковую социальную направленность деятельности, соответственно одинаково регулируются со стороны государства. Исследуемые организации занимаются оказанием услуг по водоснабжению и водоотведению и являются естественными монополиями в своих зонах обслуживания. Но между этими предприятиями имеются принципиальные различия, которые и определяют, по нашему мнению, разницу в уровне развития и качестве предоставляемыхуслуг населению по водоснабжению и водоотведению.

Первое принципиальное различие - правовые форма собственности исследуемых предприятий. Как было выше изложено, реформирование коммунальной отрасли в зарубежных странах проходило в рамках общих программ приватизации публичной собственности. C целью улучшения питьевого водоснабжения и канализационных услуг населения, развития этой области и повышения ее эффективности по Распоряжению Президента Республики Азербайджан №252 от 11 июня 2004-го года было создано Акционерное Общество «Азерсу». Все акции ОАО «Азерсу» были переданы и принадлежат до сих пор государству. Приватизация проводилась с учетом того, что государственные предприятия - это, прежде всего, национальные обязательства, а не национальное имущество. Поэтому собственность и контроль над государственными и муниципальными предприятиями и активами предприятия ЖКХ было передано в частный сектор, приносящий доход на основе конкуренции без передачи имущественных прав. В этом случае к основным методам приватизации (продажа акций, частные инвестиции в госпредприятия, разукрупнение предприятий, выкуп предприятий их менеджерами или работниками) относится аренда и подряд, а также передача государственных и муниципальных предприятий в управление частным менеджерам, то есть произошла приватизация управления и результатов деятельности.

Основные функции ОАО «Азерсу» заключаются в управлении учреждениями, находящимися в его подчинении, организация обслуживания систем водоснабжения и канализации на терри- тории Республики, координация их деятельности и контроль за их работой, а также разработка и подготовка предложений по осуществлению и реализации государственной политики в этой области.

МУП «ЖКХ «Холмские» с 1992 года является хозяйствующим субъектом, обладающим правами юридического лица по законодательству Российской Федерации, имеет самостоятельный баланс, расчетный счет, печать со своим наименованием, бланки, осуществляет свою деятельность в соответствии с законодательством Российской Федерации. Предприятие имеет административный тип управления, контролируемый со стороны государства.

В общих чертах деятельность всякой организации заключается в преобразовании ресурсов для достижения результатов. В производственных процессах организация путем использования сырьевых, трудовых, энергетических и других ресурсов создает свой конечный продукт. Рассмотрим перечень ресурсов, которые использует любое предприятие, и оценим потенциал каждого. В данной статье мы поэтапно рассмотрели трудовые, материальные и денежные ресурсы на сравниваемых предприятиях. От эффективности использования этих ресурсов зависит развитие сферы ЖКХ и очень важно определить наиболее эффективную модель управления ими.

Как отмечалось ранее, все акции ОАО «Азерсу» принадлежат государству и монополизированы. Вместе с тем это не мешает обществу функционировать как коммерческой, конкурентоспособной, финансовоустойчивой и прибыльной организации со всеми признаками рыночных отношений. На систематической основе реализуются программы развития по всем направлениям деятельности. Одной из таких программ, направленной на стабильное функционирование является «Программа по мотивации труда». Это обусловлено тем, что в ОАО «Азерсу», так же как и в МУП «ЖКХ «Холмские» на сегодняшний день проблема квалификации кадров стоит острее, чем в любой другой отрасти экономики. Трудовые ресурсы в ЖКХ - определяющий фактор качества предоставляемых услуг. В ОАО «Азерсу» существует профсоюзная 
организация, активно работающая совместно с отделом по трудовым ресурсам в направлении повышения мотивации и привлекательности труда для квалифицированных сотрудников, ежегодно проводит конкурсы по номинациям «работник года», «лучший технический работник года», «лучший инженер года» и победителей премирует, вручает грамоты, дипломы, кубки победителей. Премирование представляет собой денежную сумму в размере 1000AZN, что составляет 54 тыс.руб. по курсу ЦБ на 15.06.15г, зарубежные туристические путевки.

С 2014 года в ОАО «Азерсу» введена новая мотивационная программа, инициатором и разработчиком которой является отдел кадров. Новаторская программа нацелена на увеличение трудовой привлекательности и усиления мотивации труда. Работникам «Азерсу» были предоставлены льготные цены во всех сферах городской жизни: парфюмерные и текстильные брендовые магазины, тренажерные залы, спортклубы, туристические фирмы, развлекательные учреждения, рестораны и др. Был заключен ряд договором между данными перечисленными организациями города и «Азерсу» о предоставлении специальных уникальных льготных цен касательно персонала («Азерсу»). Предприятия города так же охотно пошли на подобные деловые заключения с ОАО «Азерсу», так как для них это потенциальные постоянные клиенты. Приняли участие более 100 местных и зарубежных организаций и частных компаний. Таким образом, задействованы социально-экономические методы воздействия на мотивацию и привлекательность труда. Это целая система мотивов и стимулов, побуждающих всех работников плодотворно трудиться и ценить свое рабочее место. С повышением привлекательности вакансии понижается текучесть кадров. На данный момент «АзерСу» стоит наряду с другими нефтяными и строительными компаниями страны по трудовой привлекательности.

Другим экономическим стимулированием является ежегодный пересмотр заработной платы с учетом изменения потребительской корзины и уровнем инфляции. Так, например, в ноябре 2013 года заработная плата максимально повысилась в пределах допустимых рамок на 20\%, что для МУП «ЖКХ «Холмское» не свойственно.

С увеличением процента инфляции заработная плата в МУП «ЖКХ «Холмское»не была повышена с учетом данного показателя, что является дисбалансом в покупательской способности работников ЖКХ. Сравнительная характеристика показала, что среднемесячная зарплата МУП «ЖКХ «Холмское» лишь в 2 раза превышает минимальный прожиточный минимум по Краснодарскому краю [3].

Эффективность деятельности предприятий ЖКХ в условиях ограниченности ресурсов прямо зависит от выбора системы мотивации работников. Результаты социального анкетирования работников по произвольной выборке позволили оценить целесообразность и успешность мотивационных программ зарубежной компании и российской. Все мотивирующие факторы рассмотрены с точки зрения их эффективности влияния на повышение производительности труда. В основу анализа включены факторы, по нашему мнению, оказывающие наибольшее влияющие на мотивацию труда работников в целом, в том числе в сфере ЖКХ. Результаты анализа приведены в таблице 2 .

Результаты проведенного исследования показали, что в ОАО «Азерсу» уровень оценок в разрезе мотивационных факторов в 2 раза выше, чем в МУП «ЖКХ «Холмское». Очевидно, что недостаточно внимания уделяется в МУП «ЖКХ «Холмское» решению социальных проблем, не все меры применяются по повышению эффективности управления персоналом, оставляют желать лучшего санитарно-гигиенические условия труда и уровень заработной платы, как одного из важнейших мотивационных факторов труда. При отлаженной системе набора и отбора персонала, слабым участком работы кадровой службы является мотивация работников в целом и рабочих специальностей в частности.

Для повышения мотивации работников в ОАО «Азерсу» использует практику обучения потенциальных работников и проведения экзамена, по результатам которого принимается решение о возможности приема на работу на вакантную должность. Без подготовки профессиональных кадров для системы ЖКХ даль- 


\section{Сравнительный анализ влияния факторов на повышение мотивации труда работников МУП «ЖКХ «Холмское» и ОАО «Азерсу»}

\begin{tabular}{|c|c|c|}
\hline \multirow{2}{*}{ Факторы } & \multicolumn{2}{|c|}{ Средний уровень оценки } \\
\hline & $\begin{array}{l}\text { МУП «ЖКХ } \\
\text { «Холмское» }\end{array}$ & ОАО «Азерсу» \\
\hline Организация труда & 2,99 & 4,52 \\
\hline Содержание работы, которую приходится Вам выполнять & 2,79 & 4,81 \\
\hline Санитарно-гигиенические условия труда & 2,74 & 4,75 \\
\hline Уровень заработной платы & 2,64 & 4,29 \\
\hline Система премирования & 2,76 & 4,42 \\
\hline Отношения в коллективе & 2,83 & 3,95 \\
\hline Отношения с руководством & 2,99 & 4,18 \\
\hline Отношения администрации к запросам работников & 3,03 & 3,81 \\
\hline Перспективы роста & 3,00 & 3,53 \\
\hline Объективность оценки работы руководством & 2,87 & 3,68 \\
\hline Возможность обучения и повышения квалификации & 3,64 & 4,59 \\
\hline $\begin{array}{l}\text { Степень своей информированности о положении дел в компании и перспективах } \\
\text { его развития }\end{array}$ & 2,86 & 5,0 \\
\hline Степень обеспеченности всем необходимым для работы & 2,83 & 4,21 \\
\hline Решение социальных вопросов & 2,49 & 3,96 \\
\hline
\end{tabular}

нейшее успешное реформирование отрасли, на наш взгляд, не представляется возможным. Таким образом, «Азерсу» отсеивает квалифицированные кадры для своих вакансий. Такой подход представляется конструктивным, так как по нашему мнению развитие отрасли без квалифицированных кадров не представляется возможным. Используемая в настоящее время практика МУП «ЖКХ «Холмское» приема на работу по собеседованию не всегда оправдана, в результате, как показывает опыт, качество трудовых ресурсов в сфере ЖКХ остается низким. Так, по мнению П. Жбанова рынок услуг сферы ЖКХ и рынок труда практически не связан, что требует разработки программы подготовки кад- ров и разработки профессиональных стандартов для сферы ЖКХ. Специалисты пришли кединому мнению, что в сферу ЖКХ следует привлекать хорошо подготовленных специалистов, менеджеров с профильным образованием.

По мнению А. Широкова разработка профессиональных стандартов для сферы ЖКХ, привлечение в сферу молодых специалистов на фоне реформирования сферы ЖКХ становится особенно актуальной проблемой. Эту работу предстоит выполнить молодым специалистам, имеющим необходимую квалификацию. В этой связи интерес молодежи к получению специализированного образования чрезвычайно высок [4]. 


\section{Управление модернизацией}

Квалифицированные кадры являются залогом успешной модернизации отрасли и, опираясь на опыт OAO «Азерсу», в процессе модернизации основных фондов жилищно-коммунального хозяйства, следует уделить этому особое внимание. МУП «ЖКХ «Холмское», имея квалифицированных кадров в резерве, может использовать модернизированную технику, современные технологии и повысить эффективность производства.

В условиях конкуренции и необходимости снижать расходы, а соответственно искать варианты учета расходов, проблема экономного использования ресурсов в целом и водных в частности, приобретает огромное значение. Государственные службы, правительственные инспекции и коммерческие предприятия заняты поиском средств учета и контроля потребления питьевой воды, как одного из основных сегментов материальных ресурсов. Исследования показали, что традиционные водяные счетчики, направленные на измерение общего количества потребленной воды не предоставляют информации о времени суток потребления. Вместе с тем, применение тарифов, способных регулировать потребление во времени, возможно, только при наличии информации о количестве и времени потребления воды. Интеллектуальные счетчики являются экономичным средством для получения подобной информации, позволяя ценообразующим организациям вводить дифференцированные тарифы на потребление в зависимости от времени суток и времени года, проводить мониторинг потребления и, следовательно, управлять потреблением, снижая излишний расход ресурсов [5].

ОАО «Азерсу» приступило к установке счетчиков нового (предоплатные) типа в мае 2012 года, на первоначальном этапе их обладателями стали абоненты промышленной и коммерческой групп. В октябре 2012 года начался процесс обеспечения устройствами абонентов из группы «Население». Для абонентов из категории населения водные счетчики устанавливаются сотрудниками метрологических отделов местных участков водоканала бесплатно - за счет государства, а другим группам абонентов - за их собственные средства.
Принцип данных счетчиков нового типа (SMART-счетчики) заключается в компьютерной централизации данных абонентов и перевод их на предоплатную основу. Счетчик идет в комплекте со смарт-картой, предназначен для измерения объема питьевой воды, протекающей по трубопроводу в системах водоснабжения, регулирует его отпуска потребителю в зависимости от суммы предварительной оплаты.

Как это работает на практике? Абонент загружает денежные средства в терминалах оплаты на смарт-карту. После чего карта вставляется в счетчик для считывания денежных средств. Счетчик автоматически начисляет абоненту эквивалентное количество кубометров воды, по истечении которых счетчик перекрывает подачу воды в квартиру до следующей загрузки денежных средств.

Таким образом, мы плавно перешли к вопросу денежных ресурсов, поток поступлений которых максимализировался с переходом на предоплатную систему расчета с потребителями. Ранее дебиторская задолженность организации в процентном соотношении была, как и в МУП «ЖКХ «Холмское». Уже к концу 2013 года (за 1,5 года после установки смарт-счетчиков) дебиторская задолженность ОАО «Азерсу» снизилась на 25\%. Переход от механических водосчетчиков к интеллектуальным обеспечил нормализацию денежного потока от населения по оплате услуг и способствовал рациональному расходованию водных ресурсов. Установка счетчиков нового поколения продолжается и в настоящее время до 100\% перехода на них.

Высокая дебиторская задолженность является основной проблемой МУП «ЖКХ «Холмское» на сегодня. Именно несвоевременное и запоздалое поступление денежных средств за ЖКУ является одной из причин несостоятельности предприятия к модернизации и другим восстановительным работам по основным фондам. Ежегодно сумма дебиторской задолженности увеличивалась на 29,7-43.3\%. Высокая дебиторская задолженность способствует понижению финансовой устойчивости. Повышение кредиторской задолженности как следствие неплатежеспособности предприятия. 


\section{Тренды и управление 3(11) • 2015}

Мониторинг и контроль всех сегментов потребителей также является залогом ресурсосбережения. В данном направлении, несомненно, полезным является опыт ОАО «Азерсу», который осуществил четырехлетнюю программу развития инфраструктуры ЖКХ. Одновременно с программой был запущен проект AzersuCIS для сбора и хранения данных инфраструктуры, необходимых для эффективной эксплуатации и технического обслуживания систем. Проект CIS - это передовое решение для управления городской инфраструктурой и состоянием окружающей среды, обеспечивший безопасность данных и доступ к картам и информации для планирования, производства, эксплуатации и ликвидации аварийных ситуаций. ОАО «Азерсу» внедрило геоинформационную систему, которая позволила осуществлять сетевой анализ и моделирование инфраструктуры питьевой и сточных вод, проводить географическую инвентаризацию инфраструктуры дождевых вод. Система направлена на предотвращение потери воды и позволяет в централизованном порядке управлять инфраструктурами питьевых, сточных и дождевых вод, проводить управленческие работы научастках. В информационной базе отражена информация о количестве этажей и блоков здания, числе проживающих в здании граждан, наличии коммерческих структур, фото здания и др. Вся информация в режиме онлайн заносится в электронную карту. Нумерация зданий позволяет ОАО АзерСу иметь точную информацию о наличии аварийных ситуаций, что позволяет реагировать на ситуацию более оперативно и, наряду с этим, существенно снижает расход питьевой воды. Сотрудники предприятия, используя мобильные устройства, могут точно знать о том, сколько в здании проживает людей, сколько имеется коммерческих структур. Для получения информации использовано приложение, которое полнофункционально в среде операционных систем Android и iOS.

Реализацией проекта Azersu CIS занималась компания Bentley, имеющая большой опыт в построении геоинформационных систем. Благодаря решениям MicroStation и MicroStation PowerDraft более 100 удаленных пользователей смогли обращаться к системе AzersuCIS через Интернет. Используя технологию пространственных баз данных, ОАО «Азерсу»всего за семь месяцев сэкономила 800000 долл. США [6].

Рассмотрев основные идеи и опыт зарубежного ЖКХ на примере ОАО «Азерсу», мы продемонстрировали механизмы рационального использования трудовых ресурсов, ресурсосбережения, а также максимализации денежного потока. МУП «ЖКХ «Холмское» были даны рекомендации по освоению зарубежного опыта. C 2014 года МУП «ЖКХ «Холмское» пересмотрело свою политику управления кадрами с учетом результатов анкетирования. Для составления плана оздоровления состояния кадров в МУП «ЖКХ «Холмское» пункты анкетирования рассмотрели по степени значимости. Исходя из данного распределения мотивирующих факторов, МУП «ЖКХ «Холмское» составило план оздоровления состояния кадров, начиная с более важных. Были внесены поправки и проведены работы по ликвидации неблагоприятных условий и мотивации труда и выбраны методы и мотивационная политика, включающая административные, экономические и социально-психологические методы. Пересмотрена была заработная плата с учетом инфляции и максимально повысилась в пределах допустимых рамок со стороны РЭК (регионально-экономическая комиссия).

За первое полугодие оценки анкетирования повысились на $30 \%$. Текучесть кадров снизилась на $25 \%$, неудовлетворенность своей работой уменьшается. Реализация намеченной программы в полном объеме за 2 года призвана снизить дефицит квалифицированной рабочей силы в анализируемом МУП «ЖКХ «Холмское».

Касательно внедрения новых технологий в основные средства, ситуация остается лишь в планах. Государство пока не в состоянии взять на себя подобные расходы по модернизации основных средств и переводу абонентов на предоплатную основу. Однако законодательство Российской федерации сопутствовало уменьшению дебиторской задолженности внесением поправок в нормативно-законодательные документы. После внесения поправок в «Постановление Правительства РФ от 06.05.2011 N 354 (ред. от 14.02.2015) “О предоставлении коммунальных услуг собственникам и пользователям помещений в многоквартирных домах и жилых домах» 


\section{Управление модернизацией}

в п.115 и п.117 данный показатель, тем не менее, увеличился на 8,1\% в 2014 году. Таким образом, данные преобразования оказались не эффективными для МУП «ЖКХ «Холмское» [7].

Общая практика функционирования коммунальных предприятий в Европе показывает, что в этих странах существует много гибких форм и методов управления объектами публичной собственности с использованием возможностей частной инициативы, частного капитала и рыночной конкуренции. В целом, наиболеезначимыми понятиями в праве указанных нами стран, связанными с предоставлением коммунальных услуг, являются концессии, приватизация и акционирование.
Изучение передового зарубежного опыта выявляет следующие основные направления его применения в российских условиях:

- $\quad$ неполная приватизация;

- $\quad$ дисциплинизация абонентов;

- $\quad$ системный подход к эффективному использованию трудовых ресурсов;

- переход ЖКХ на механизм рыночных отношений;

- модернизация основных фондов;

- $\quad$ монтиторинг системы водоснабжения посредством новых технологий;

- $\quad$ развитие системы ресурсо- и энергосбережения (приборы учета нового поколения).

\section{Библиография}

1. Янковский Н.Я. Правовые основы функционирования коммунального хозяйства в Европейских странах. - Владивосток: Сфера ЖКХ, 2007, 340с.

2. Комиссарова Л.А. Европейский опыт в управлении жилищно-коммунальным хозяйством» //Вестник НГИЭИ. 2011. №5 (6)

3. Дейнега В.А., Оруджева М.А. Анализ структуры трудовых ресурсов жилищно-коммунального комплекса и инструменты повышения эффективности их использования //Экономический анализ: теория и практика.-Москва Фин.издат., 2015г.

4. http://gkh-altai.ru/all-news/kadrovaya-problema-v-sfere-zhilishhno-kommunalnogo-xozyajstva-nasegodnyashnij-den-stoit,-pozhaluj,-ostree,-chem-v-lyuboj-drugoj-otrasti-ekonomiki\%C2\%A0rossii2.html

5. А.В.Гинзбург, Основные направления государственной технической политики модернизации ЖКХ российской федерации//«Новости теплоснабжения» №12(40) декабрь, 2003 г.

6. http://www.bentley.com/ru-RU/Engineering+Architecture+Construction+Software+Resources/User+Stories/ Be+Inspired+Project+Portfolios/Azerbaijan/GIS+based+Infrastructure+Asset+Management+Azersu+OJSC.htm

7. http://www.consultant.ru/document/cons_doc_LAW_175645/@КонсультантПлюс, 1992-2015

\section{References (transliterated)}

1. Yankovskii N.Ya. Pravovye osnovy funktsionirovaniya kommunal'nogo khozyaistva v Evropeiskikh stranakh. - Vladivostok: Sfera ZhKKh, 2007, 340s.

2. Komissarova L.A. Evropeiskii opyt v upravlenii zhilishchno-kommunal'nym khozyaistvom» //Vestnik NGIEI. 2011. №5 (6)

3. Deinega V.A., Orudzheva M.A. Analiz struktury trudovykh resursov zhilishchno-kommunal'nogo kompleksa i instrumenty povysheniya effektivnosti ikh ispol'zovaniya //Ekonomicheskii analiz: teoriya i praktika.-Moskva Fin.izdat., 2015g.

4. http://gkh-altai.ru/all-news/kadrovaya-problema-v-sfere-zhilishhno-kommunalnogo-xozyajstva-nasegodnyashnij-den-stoit,-pozhaluj,-ostree,-chem-v-lyuboj-drugoj-otrasti-ekonomiki\%C2\%A0rossii2.html

5. A.V.Ginzburg, Osnovnye napravleniya gosudarstvennoi tekhnicheskoi politiki modernizatsii ZhKKh rossiiskoi federatsii//«Novosti teplosnabzheniya» №12(40) dekabr’, 2003 g.

6. http://www.bentley.com/ru-RU/Engineering+Architecture+Construction+Software+Resources/User+Stories/ Be+Inspired+Project+Portfolios/Azerbaijan/GIS+based+Infrastructure+Asset+Management+Azersu+OJSC.htm

7. http://www.consultant.ru/document/cons_doc_LAW_175645/CKonsul'tantPlyus, 1992-2015 